DOI: $10.17747 /$ TEDS-2020-8-11

Elena V. Vasilieva ${ }^{1}$

Department of Business Informatics

Financial University under the Government of the Russian Federation

Moscow, Russia

1evvasileva@fa.ru

\title{
DESIGN THINKING IS A METHODOLOGY FOR CREATING INNOVATIONS AND DEVELOPING HUMAN CREATIVITY
}

\begin{abstract}
Not so long ago, human resources were perceived as the main participant in business processes and as an integral part of the company's organizational capital. However, automation and the introduction of industrial technologies 4.0 replace people with programs, robots, chatbots, etc. But this does not mean that in the new era, human functions in the process will be reduced to a minimum. Goals focused on the implementation of new business tasks in the face of constant changes will require a person to work in a team, effectively use their competencies, be focused and successful, think outside the box and find original solutions, actively use the accumulated individual and collective intellectual capital. This will make the application of various techniques of the design thinking methodology an integral part of human activity in the company. The author gives an overview of the tools and techniques of design thinking, shows the features of their application. Highlights the specifics of organizing collective creative work and maintaining an atmosphere of trust and creativity. Provides a list of popular digital services for organizing teamwork. The development of the design thinking approach was achieved through the new methodology - Platform Innovation Kit, which is used for designing an ecosystem platform. Platform design canvases help startups and corporations launch and scale businesses on digital platforms.

Keywords - management; breakthrough innovations; soft skills; design thinking; creativity; Platform Innovation Kit
\end{abstract}

\section{INTRODUCTION}

In the context of digitalization of the economy and society, the requirements for the competence of specialists are changing. A modern organization needs an employee who is competent in their professional field, has knowledge of information technology, but most importantly - their skills of interaction with other people, emotional intelligence, empathy, teamwork skills, creative abilities and desires for self-realization and professional growth. Soft skills are extremely important today when performing professional tasks in an inaccurate initial formulation. They allow employees to move on to new tasks that are difficult to automate. And they help you quickly adapt to a changing environment.

You can also teach soft skills using one of the most discussed Design Thinking methodologies today.

\section{HOW TO CREATE BREAKTHROUGH INNOVATIONS?}

Design thinking is a methodology for designing innovative products based on technologies for managing people's collective intelligence and creativity. The author of this methodology is David Kelly, founder of the design Agency IDEO. Today it is developed at d.school (Stanford) and Hasso Plattner Institute (Potsdam). It combines various developments in the field of marketing and research of consumer needs, development of creative skills of a person and generation of ideas, visualization $[1,2,3]$. By applying design thinking, people learn to go beyond standard methods and established stereotypes when solving problems. They become creative and flexible in decision-making, feeling and emotionally fulfilled, understanding other people and themselves.

For more than 5 years, we have been actively implementing design thinking techniques in the educational process and applying it to solve adaptive problems both in the field of education 
for departments of the Financial University and its partners, and conducting design seminars at the invitation of organizations in various industries. Such design seminars allow you to develop teamwork and collaboration skills, mutual understanding and involvement in the problem of personnel, when creating a package of innovative ideas, team members also feel responsible for their implementation.

The integration of design vision and cognitive techniques allowed us to form a successful system for creating breakthrough innovations. The sequence of the design thinking process consists of several stages: from empathy and focusing on the problem-to generating ideas and choosing the best, and then - to developing a prototype and testing it. Popular tools include the Empathy Map, Customer journey map (CJM), How Might We (HMW), Current - Future-Barriers (CFB), SCAMPER, World café, etc. [4].

The empathy stage sets up the innovation developer to understand the consumer's emotions and feelings. He studies the client's problem, takes his place, looks at the product through his eyes. Partisan Ethnography is a method of covert observation of the target audience in real conditions. It includes a variety of techniques for collecting information, including photo and video shooting techniques, observing the user in a context where researchers spend the whole day next to a key

1 This line is reserved for Copyright Notice code representative of the target audience, literally walking behind them, or performing user tasks themselves using the "moccasins" technique.

One of the principles of Design thinking is to visualize and record ideas. Since the most important thing in the team's work during brainstorming is to hear, understand and briefly formulate any idea, and then be able to remember it after a while and convey it to an outsider, stickers and markers are indispensable assistants in the classroom. Visualization allows you to simply and clearly convey the meaning, present a new idea. Logical and visual thinking are activated simultaneously. For a visual representation of ideas in the IDEO building mind maps.

When studying the user experience, the entire chain of actions is studied and recorded in the outline of the CJM user path. Building a COM canvas is usually aimed at a detailed description of the process with the identification of the emotional component of its participants, as well as at developing scenarios to eliminate barriers to the user's business tasks. Each stage of the analyzed process can be divided into four categories (PEDPL model): previous experience - PreExperience; problems of current experience - During Experience; results after completion - Post-Experience, as well as missed alternatives, lost Experience - Lost Experience [4].

The project team can fill in the COM outline manually on a flipchart sheet using stickers, in Google spreadsheet, and in archi Internet services, miro.com (Fig. 1), mural.ly, uxpressia.com.

Fig. 1. Example of a CRM tool: Miro.com

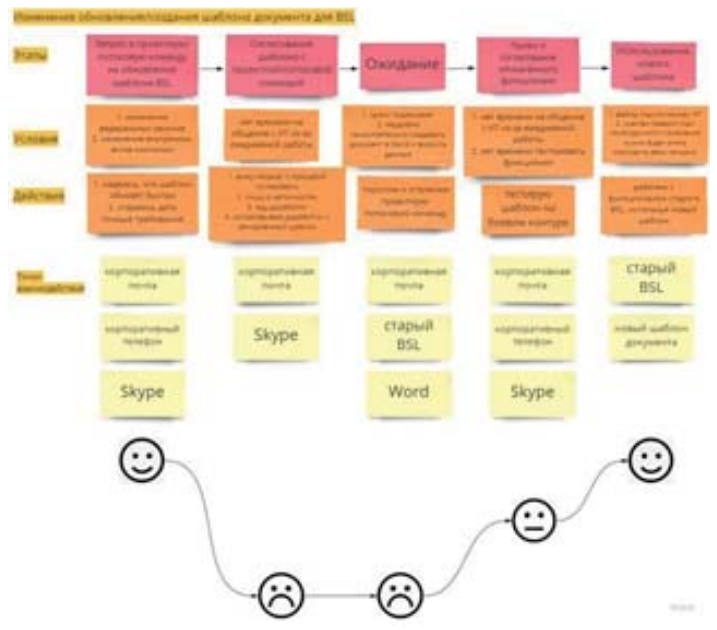


During the "Generation" stage, a large number of possible solutions are created during brainstorming. At this stage, the techniques work well: How Might We, Current - Future - Barriers, SCAMPER, and World café [4].

\section{THE PLATFORM DESIGN METHODOLOGY}

A new platform design methodology has been developed and is Being successfully tested in practice for designing an ecosystem platform. This Is Platform Innovation Kit [5,6].

All scenarios of using the company's products or services, including joint offers with partners, create a special ecosystem

Today, many companies that have chosen digital transformation as their main strategy are moving to a new paradigm of ecosystem platform thinking, which defines the requirements for how to build working processes and solutions. Companies such as Sberbank, Yandex, and others are developing consumer services as an ecosystem. Mail.ru Group.

The basis of the ecosystem is still the platform. The ecosystem has open interfaces or provides compatibility of various services, its functionality includes identification services, rapid data exchange, etc., and unified software interfaces make it easier to connect to the platform.

The European payment Directive PSD 2, aimed at increasing competition in the payment services market, gave a boost to the ecosystem. With its approval, banks began to provide open access to the API (Application Programming Interface - the application Programming Interface that developers can use to create their own applications to work with the service). Providing services in an open format (open banking) has increased competition, forcing us to look at the possibilities of the value proposition more broadly. The Bank is integrated into the value chain in many segments through the ecosystem, and in return, partners get access to customer data.

Cutting-edge companies aim to improve the experience for their customers, not only in their field, but throughout their life. Therefore, their new offers are built around possible customer needs for non-core services. An ecosystem based on the "LifeStyle Banking" principle, where a single mobile banking app can cover almost $100 \%$ of a client's potential needs in any area of life - from buying groceries to renting a home, etc. According to this strategy, banks are starting to conduct projects in healthcare, education, retail, and partly transport.

The Sberbank ecosystem, for example, spanned several verticals at once. If in 2019 it included 20 different companies, now there are already 48 ecosystem projects, including education (Business environment), employment (Rabota.ru), telemedicine (together with DocDoc), online Commerce (Yandex.Market, Bringly), food delivery (together with Mail.Ru - DELIVERYCLUB), real estate, etc.

Platform design canvases help startups and corporations launch and scale businesses on digital platforms. This methodology contains a number of visual templates (canvases) that allow designers to collect key transformation ideas at different stages of design, closing the white spots of uncertainty, and move towards the goal, including creating knowledge bases for future projects. Canvases, in fact, allow you to draw a business layout. Visualization enables the project team to work effectively, reduce the risk of data loss, and support the creative process.

Platform Innovation Kit tools include: Platform-BusinessModel, Platform Mapping, PlatformStakeholder-Relationship, Ecosystem-Journey, Context study canvas, StakeholderPersona, Platform-Architecture.

At the research stage, ecosystem objects are described and the organization's potential is analyzed. A good and simple framework for displaying existing benefits (assets) for an organization is the VRIO framework. The map of the platform communication ecosystem reflects the relationships between end and intermediate peer-to-peer (peer-to-peer) consumers (PC) and producers (PP), partners (RA), and platform owners (PO).

The potential and motivation matrix compares all current and potential value flows to understand what one ecosystem participant can give to another. All schemas serve as the basis for the Platform Business Model Canvas. 


\section{CONCLUSION}

The platform strategy is an "interactive" product, and with the generation of network effects, the value of the platform usually increases. These tools allow you to generalize available materials, formulate development hypotheses, identify participants and their relationships in the process of delivering a service (product) to the consumer along the entire path of contact with the brand. Platform design, as well as customer experience design, currently only acquire their own tools and techniques, but now we can talk about the diversity and benefits of visual schemes of design thinking and Platform Innovation Kit for management and innovation.

Design thinking opens up good prospects for finding innovative ideas both in the course of collective intellectual work and in independent creativity. The effectiveness of brainstorming is provided by structuring information using various canvases. The activity of thinking is supported by the workouts and switching to the other steps of research, discussion or development of the prototype. Iteration of the process and positive feedback reduces risk aversion and teaches you to analyze errors. Different thinking styles are involved. Design thinkers are able to trust their intuition, turn on their imagination, think outside the box and not stop there. Thus, design thinking is an important tool for human development and is necessary for implementation in the educational process and practice of working with personnel.

\section{REFERENCES}

[1] T. Kelley, D. Kelley, Creative Confidence Unleashing the Creative Potential Within Us All. NY: Barnes \& Noble, 2013.

[2] J. Liedtka, T. Ogilvie, Designing for Growth: A Design Thinking Toolkit for Managers. Columbia University Press, 2011.

[3] M. Levrik, P. Link, L. Leifer, The Design Thinking Playbook: Mindful Digital Transformation of Teams, Products, Services, Businesses and Ecosystems. NY : Wiley, 2018.

[4] E. Vasilieva, Design thinking: a little bit about the approach and a lot about the tools of creative thinking, learning client requests and creating ideas: monograph. Moscow: RU-SCIENCE, 2018. (In Russ.)

[5] 12 Patterns of Platform Design to kickstart Innovation Strategies. Available at: https:// stories.platformdesigntoolkit.com/12-patterns-ofplatform-design-to-kickstart-innovationstrategies-500c6dec9c3b (accessed 02.09.2020).

[6] Platform Design Toolkit. Available at: https://ab-w.com/method_meetup/ platform_design (accessed 02.09.2020). 